\title{
Article
}

\section{Adaptive expertise - a characteristic of expertise in outdoor instructors?}

Mees, Alice, Sinfield, Dean, Collins, Dave and Collins, Loel

Available at http://clok.uclan.ac.uk/31616/

Mees, Alice, Sinfield, Dean, Collins, Dave and Collins, Loel ORCID: 0000-00027478-1140 (2020) Adaptive expertise - a characteristic of expertise in outdoor instructors? Physical Education and Sport Pedagogy, 25 (4). pp. 423-438. ISSN $1740-8989$

It is advisable to refer to the publisher's version if you intend to cite from the work. http://dx.doi.org/10.1080/17408989.2020.1727870

For more information about UCLan's research in this area go to http://www.uclan.ac.uk/researchgroups/ and search for < name of research Group>.

For information about Research generally at UCLan please go to http://www.uclan.ac.uk/research/

All outputs in CLoK are protected by Intellectual Property Rights law, including Copyright law. Copyright, IPR and Moral Rights for the works on this site are retained by the individual authors and/or other copyright owners. Terms and conditions for use of this material are defined in the policies page.

\section{CLoK}

Central Lancashire online Knowledge www.clok.uclan.ac.uk

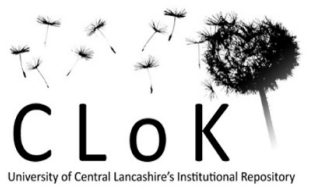




\title{
Adaptive expertise - a characteristic of expertise in outdoor instructors?
}

\author{
Alice Mees $^{\mathrm{a}, \mathrm{e}}$, Dean Sinfield ${ }^{\mathrm{b}, \mathrm{c}}$ Dave Collins $^{\mathrm{d}, \mathrm{e}}$ and Loel Collins ${ }^{\mathrm{f}, \mathrm{b}} *$ \\ a. Outward Bound Trust, and Institute of Coaching and Performance, University of \\ Central Lancashire, Preston, Lancashire \\ b. Plas y Brenin, National Outdoor Centre and \\ c. Institute of Coaching and Performance, University of Central Lancashire, Preston, \\ Lancashire \\ d. Moray House School of Education and Sport, University of Edinburgh \\ ${ }^{e}$ Grey Matters Performance Ltd.

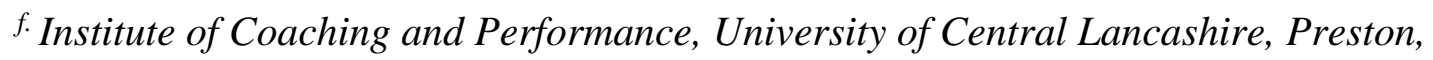 \\ Lancashire
}

*Loel Collins: LCollins2@uclan.ac.uk 

Abstract:

Background: Over the past 10 years, research has started to investigate the pedagogic practices of instructors and coaches working in adventure sports settings. Outdoor instructors face particular challenges regarding the impact the dynamic environment has on the coaching process and their students. This challenging combination of factors obliges the instructor to be agile in response. We propose that this adaptive expertise is characteristic of these factors and that adaptability may be a beneficial focus of outdoor instructor training and education.

Purpose: The major aim was to identify if adaptive expertise is an attribute of outdoor instructors? And if so, what are its characteristics in this context?

Research design and data collection: We applied a mixed methodology to a sample of outdoor instructors $(n=64)$. The instructors were asked to complete a quantitative adaptive expertise inventory. We then interviewed a selected subsample $(\mathrm{n}=12)$.

Participants and setting: Quantitative data was collected from outdoor instructors working in the UK $(n=64)$. The sample consisted of instructors qualified to work independently with groups in adventurous settings in a range of activities. Qualitative data was collected from a smaller sample $(n=12)$ via a series of thematically analysed semi-structured interviews.

Findings: Results suggest that the participating outdoor instructors have high levels of adaptive expertise. A characteristic of that adaptive capacity is a combination of skills revolving around reflection, metacognition, and situational awareness. There were differences, however, between less and more experienced outdoor instructors in their adaptive capacity, with less experienced instructors being adaptive to a lesser extent.

Conclusions: The implication is that further research is worthwhile to examine the development of instructors' adaptive capacity. The training and education of outdoor instructors requires pedagogic approaches that facilitate and engender adaptability, flexibility and agility in neophyte instructors. 
Keywords: Adaptability, Adventure-sport coaching, Adventure-sport Leadership

\section{Introduction}

Outdoor instructors work in dynamic environments (Collins and Collins 2016b; Collins, Simon, and Carson, 2018) and encounter situations brought about by the synergy of complex tasks, dynamic environments, and objectives to develop the individual (Collins and Collins 2016a, 2016b). Capable instructors must manage challenges and demonstrate a pedagogical and technical agility to meet each novel issue as it arises or, ideally, through anticipating and countering that issue. Reflecting this dynamic environment, we hypothesised that Hatano and Inagaki’s (1986) notions of adaptive expertise (AEx) could characterise expert outdoor instructors' practice. AEx has been a popular concept since the mid-1980s and, more recently, has been discussed in the outdoor leadership context by Tozer, Fazey, and Fazey (2007). Since this proposal, however, explicit investigation of adaptive expertise in outdoor instructors has not received further attention. More recently, Hutton, Ward, Gore, Turner, Hoffman, Leggatt, and Conway. (2017) proposed six principles for developing AEx - namely, flexibility-focused feedback, concept-case coupling, tough case time compression, case scaling proficiency, complexity preservation, and active reflection. All or some of these could form the basis of pedagogic approaches utilised in the development of outdoor instructors. Logically, however, we must first ascertain if AEx is apparent in Outdoor Instructor practices. Accordingly, we employed a mixed methodology to address the following questions. Firstly, is AEx an attribute of outdoor instructors? Secondly, if so, what are its characteristics in this context?

\section{What is adaptive expertise?}

AEx contrasts with and builds on routine expertise (Hatano and Inagaki, 1986; Hatano and Oura 2003). Both notions of expertise demand the capacity to perform 
standard tasks and routine functions without error. In the first part, routine expertise may be considered in two ways: (1) competence with parts or functional units (e.g. tying a knot, constructing a rope system, or navigating from point A to B) and (2) expertise that allows for managing a single variable in the outdoor instructional 'mess' (Simon, Collins, and Collins 2017). In contrast, AEx is characterised by efficiency and innovation in applying that knowledge to new situations and challenges (Bransford et al. 2005; Hutton et al. 2017). It is this flexible, creative, and innovative use of the competencies found in routine expertise that enables the adaptability of the adaptive expert (Trotter et al. 2017). AEx has three components: domain-specific skills, metacognitive skills, and innovative skills (Crawford et al. 2005; Hatano and Inagaki, 1986; Hatano and Oura, 2003).

Domain-specific and metacognitive skills are shared between adaptive and routine expertise (Carbonell et al. 2016; Feltovich, Prietula, and Ericsson 2012). Though metacognitive capacity may not be a measure of AEx in itself (Carbonell et al. 2016), innovation remains a defining characteristic of AEx. However this does assume that Hatano and Inagaki(1986) are correct in stating that AEx is built on routine expertise. Individual dispositions do underpin these AEx skills; for example, a comprehension of the interaction between components in routine processes and an epistemology that acknowledges and utilises new knowledge to enact a new approach (see Christian, Berry, and Kearney 2017; Collins, Collins, and Grecic 2014) both seem important. However, synthesising these multiple definitions of AEx yields the following common aspects of the domain specific knowledge: (1) a comprehension and anticipation of the situation at hand, a high level of situational awareness and demands, beyond a descriptive account (2) as possessing the technical and pedagogic skills required to 
confront that instructional situation, and (3) a self-awareness to balance the demands of the individual with that individual's abilities (Hutton et al. 2017, 83).

\section{Complex domain-specific knowledge}

As highlighted above, adaptive experts possess extensive, integrated knowledge that differentiates them from routine experts (Hatano and Inagaki, 1986). Adaptive experts appear to focus on acquiring new domain knowledge and skills to apply as opposed to learning procedures and processes: suggesting that their training and development might best require a non-routine approach, at least in its later stages. We surmised that this may also influence how one retains knowledge (e.g. procedurally, episodically, semantically), how the components of that knowledge are related and linked, and how one articulates that knowledge which would again influence the approaches employed in the development of outdoor instructors. Clearly how an outdoor instructor in trained and educated has a direct influence on the nature of their practice. Adaptive experts appear to value learning and applying knowledge and are motivated to problem solve (Bell et al. 2012; Bransford et al. 2005; Crawford et al. 2005). Commensurate with the value placed on learning, there is a willingness to challenge and replace prior assumptions and recognise gaps in knowledge. Such questioning draws on the individual's reflective capacity (Bransford et al. 2005; Crawford et al. 2005; Schwartz, Bransford, and Sears 2005) and is possibly suggestive of a sophisticated epistemology. Such views would associate adaptability and agility with a particular philosophical position which may in turn directly influence the approaches advocated in instructor training.

AEx entails recognising situations in which a routine will not suffice; comprehension of the complexity and dynamism of the situation is essential as is a capacity to predict and anticipate the outcome of a given situation. As such, an 
individual possessing AEx may build mental models of a given situation (Barnett and Koslowski 2002; Chi 2011; Wineburg 1998) and would not rely purely on procedure or routine (Olsen and Rasmussen 1989; Sonnentag, Niessen, and Volmer 2012). AEx involves a synergy of decision making processes, hypothesis construction and evaluation, and solution-finding (Crawford et al. 2005; Lin, Schwartz, and Hatano 2005). Then decisions predominantly derive from a classic decision making process emerge in pre- or post-action, but demonstrate dependence on naturalistic processes when in action. Under such time pressure or situational demands with incomplete information, the instructor may need to draw on experience and metacognitive and reflective skills. For outdoor instructors, according to Collins and Collins (2015a, 2015b, 2016b), decision making is a combination of both classic and naturalistic processes that vary depending on the context of the decision. In this respect the cognitive skills of decision making would logically form parts of any instructor developmental process and require decision making to be a focus of any pedagogic approach in instructor education

Furthermore, individuals with AEx demonstrate a capacity to self-assess their expertise, knowledge, learning, and problem solving ability (Bell et al. 2012; Crawford et al. 2005). They also possess high cognitive flexibility, deep thinking skills, and metacognitive ability (Barnett and Koslowski 2002; Bell and Kozlowski 2008; Stokes, Schneider, and Lyons 2010). These skills enable individuals to view situations in new contexts and create analogies, thus making adaptability transferable and transportable to new contexts. Also, AEx may entail viewing components as ingredients that can be reassembled differently to deal with novel situations rather than being proceduralised. Conceptualising parts as component or loose parts allows for forming new responses (innovation and creativity) and may include new knowledge (declarative, procedural, or 
conditional; Alexander, Schallert, and Hare 1991) or a new method of working that suits the context. Outdoor instructors appear to need these attributes to function safely and effectively in their adventure settings.

\section{Context for adaptive performance, conditions for adaptive expertise}

Adaptive performance is multi-dimensional and relevant to particular roles and contexts (Pulakos et al. 2000). Logically, environments that require adaptation and flexibility should require adaptive experts. Reflecting our earlier comments regarding environment, an application of Pulakos et al.'s $(2000,2009)$ taxonomy of adaptive performance (Table 1) suggests that an outdoor instructor's role appears ripe for adaptive expertise.

\section{Insert Table 1}

The environment and the degree to which the instructor has or lacks control in that context are unique characteristics of adventure sports (Collins and Collins 2016b). We argue that adaptive capacity is a factor of all good teaching, but is essential in outdoor instruction at any level. To be adaptable, an agile outdoor instructor must possess knowledge of why and under which conditions existing approaches can be utilised. The capacity to recognise a situation and select or create 'tools for the job' seem to be critical aspects of an outdoor instructor's practice. Thus, adaptive expertise may be a necessity for an agile outdoor instructor.

Thus, we ask is adaptive expertise an attribute of outdoor instructors? And if so, what are its characteristics in this context? Clearly, the findings may have an effect on the approaches we utilise in developing those instructors

\section{Method}

The approach for this study drew on the recommendations of Levitt et al. (2017) for integrity via explicit consideration of the fidelity and utility of the research. 
Reflecting on the lack of empirical data challenging the robustness of Hatano and Inagaki's (1986) proposition of AEx and Hutton et al.'s (2017) assertion of a lack of empirical research, our intention was to undertake real-world research (Robson and McCartan 2016) with a mixed methodology. Our aim was pragmatic, to ultimately provide findings that would enhance the training of outdoor instructors by demonstrating the desired end point of the developmental process. Accordingly, we employed a mixed-methods, two-stage approach, including the quantitative adaptive expertise inventory (AEI; part 1) and a qualitative semi-structured interview that was thematically analysed (part 2).

\section{Part 1}

\section{Participants}

Participants were British outdoor instructors $(n=64)$, identified via personal contact with the researchers. In line with Nash et al.'s (2012) recommendations and to ensure domain expertise, experience, and quality in terms of self-reflective ability, purposive sampling was employed based on the following criteria: (1) a minimum of three years of instruction and leadership experience since accreditation to take sole charge of a group during an adventurous activity, (2) active engagement in outdoor instruction, (3) to be working autonomously with groups, and (4) having a willingness to discuss one's professional practice. A sub-sample of more experienced instructors (ExI) was identified by (1) a minimum of five years of instructing experience since senior accreditation to either operate in more remote or challenging environments in a single activity, (2) holding three or more qualifications to enable independent leadership in a range of other activities and (3) being in positions of seniority within their organisation. 


\section{Procedure}

After obtaining institutional ethical approval and informed consent, a copy of the questionnaire was forwarded to each instructor. The 11-item AEI (Carbonell et al. 2016) is premised on adaptation as a multidimensional process. Participants were asked to anonymously complete the AEI by scoring responses to 11 questions (Table 2) with each item utilising a 5-point Likert scale.

\section{Insert Table 2}

Analysis

The responses were scored and added to create a score for each participant across the sample. Descriptive analysis and an independent t-test of the two groups were conducted using SPSS statistics version 24. Responses with two or more missing or erroneous values (marking between categories, missing questions) were removed from the data set. Following completion, participants were asked to indicate whether they would be willing to participate in the interviews (part 2).

\section{Results and discussion}

The AEI was distributed to 72 participants. Sixty-six consented and responses were received and analysed (92\% response rate). Two further AEIs were excluded for falling outside the criteria devised for completion, and one AEI contained a single erroneous response that was accepted following agreement with the research team $(97 \%$ completion rate, $\mathrm{n}=64)$.

\section{Insert Table 3}

On average, ExI $(\mathrm{M}=50.3, \mathrm{SE}=0.6)$ reported greater tendencies towards adaptability than the less experienced instructors $(\mathrm{CpI})(\mathrm{M}=45.5, \mathrm{SE}=0.8)$. Assuming 
equal variance $(\mathrm{p}=.125)$, this difference $(4.8,95 \% \mathrm{CI}[2.8,6.8])$ was significant $(\mathrm{t}(53)$ $=4.8, \mathrm{p} \leq .001)$.

\section{Insert Table 4}

AEx is an aspect of outdoor instructional practice in this sample for both $\mathrm{CpI}$ and ExI, supporting our original contention. While ExI appear to be more adaptive than their less experienced counterparts, however, $\mathrm{CpI}$ do also show a capacity for adaptability. This may be because, in order to practise as an outdoor instructor, one requires practical skills in adventure activities that themselves demand adaptability and thus is an inherent aspect of the instructor role. If such adaptability is developed through participation prior to training or instructors with adaptable traits are attracted to instruction is difficult to surmise at this point. The finding could also be due to cultural differences in the organisations employing those instructors though this requires further investigation. It seems likely that less experienced instructors may be employed in more structured workplaces with greater rules and regulations that govern practice. These findings certainly raise a question about how adaptability can be developed and nurtured in outdoor instructors, as an enhancement of practices rather than introduction of adaptability as an aspect of practice.

\section{Part 2}

\section{Participants}

A smaller convenience sample of instructors who took part in part $1(n=12)$ agreed to be interviewed $(n=6 \mathrm{CpI}, n=6 \mathrm{ExI})$.

\section{Procedure}

Reflecting the findings in part 1 , the authors designed a four-question semistructured interview guide (Willis, DeMatio, and Harris-Kojetin 1999) and piloted it with a representative sample. Following the pilot, changes were made to the prompts 
and wording before data collection. The final questions were used to guide the semistructured interviews (Table 5) but were not used verbatim. The questions and prompts were designed to be increasingly cognitively challenging: initially, stimulating recall in descriptive terms, exploring the breadth of options considered by the instructors, identifying the choice factors that affected the adoption of an approach, and finally asking the instructor to consider a hypothetical situation in which their skills could be deployed. Interviews were conducted by the first or second author, with each instructor at their convenience following an adventure activity session led by them. Data were recorded using a digital Dictaphone and securely stored electronically in mp3 file format.

\section{Insert Table 5}

Analysis

The interviewer conducted the initial analysis of transcripts. Interviews lasted between 15 and 31 minutes (mean duration, 23.41 mins). A thematic analysis was applied in four parts, following the guidance of Braun and Clarke (2010). First, interviews were transcribed verbatim, checked, and corrected against the recorded interview. Each transcription was re-read several times to comprehend the essential features (Sandelowski 1995) fully, facilitate the analysis, and highlight similarities and differences in the data. Second, the initial coding of data was done by identifying relevant and similar extracts. Third, data codes were collated into hierarchically ordered themes based on relationships and common features. Finally, the interviewers subjected these themes to review. The aim was to understand and interpret the data and, therefore, the emerging themes as a whole data set, enabling themes to be combined, broken down, and new themes to be identified. The emergence of themes at any point did not depend on the prevalence of a code, but what the theme revealed about the participants' 
adaptive abilities. To ensure inter-coder agreement, the fourth author, who was not involved in the interviewing or initial coding process, independently coded a random sample of the transcripts (40\%) to guard against misinterpretation and researcher subjectivity (Morrow 2005). Disagreements regarding these differences in codes were discussed until a consensus was reached. Participant codes (Robson and McCartan 2016) were assigned to ensure the instructors' anonymity and to avoid deductive disclosure (e.g. CpI1, ExI2).

\section{Results: Part 2a}

\section{Less Experienced instructors}

The results comprise 145 codified units leading to 13 low-order themes, five mid-order themes, and two high-order themes. A thematic table (Table 6) demonstrates the relationships between themes in a linear manner. However, it does not express the complexity of relationships in the data; these are shown more clearly in a thematic map (Figure 1).

\section{Insert Table 6 and Figure 1}

\section{Discussion}

The initial process for running the session, for CpI, begins by creating a detailed plan before starting a session. Initially the $\mathrm{CpI}$ takes into account organisational demands (e.g. logistics, safety procedures, and learning outcomes) before applying the predicted situational demands (e.g. weather and group needs) which suggest a high level of situational awareness. The CpI factors in experiences with the group, or similar groups, in other activities and explicitly draws on their prior experiences, demonstrating their reflective practice. However, this plan provides a fixed framework that ties the instructor logistically and emotionally to a particular course of action which has the potential to reduce capacity for adaptation. CpI5 commented thus: 
I'd planned in my mind to use the bottom right-hand tier of the crag, and we got to kind of... as you come round the corner [to the venue]... and instantly I saw a group on that section I wanted to use and sort of... my heart sank a little bit because I'd sort of already in my mind planned that session for there.

This emotional response suggests that a heuristics style of decision making may be at play, possibly supporting the assertions of Kahneman and Tversky (1974), McCammon (2001), and Simon, Collins, and Collins (2017). This may be prone to biases, however, because of the breadth and depth of experience; specifically this 'fixing' of the plan. These findings appear to confirm that commitment, consistency, scarcity, and familiarity act as heuristic bias in CpI's decision making. Working within the plan, the instructor makes adaptations during a session in response to the environment and the group but is constrained. These adaptations rarely result in a complete change of plan, and efforts are generally made to align with plan A. When facing a challenge, $\mathrm{CpI} 2$ felt that 'it would have been best to go with the original... well, as much of the original plan as we could do'. The scale, depth, and attachment to the planning is consistent across all six $\mathrm{CpI}$ and is possibly illustrative of an implicit recognition of the need for a broad and deep experience to support the naturalistic decision making inaction and also an assumption that classic decision making processes are better than those that are naturalistic . This would suggest a value in encouraging critical reflection as an aspect of instructor development may strengthen the perceived weaknesses of the naturalistic decision making aspect.

For the $\mathrm{CpI}$, future challenges are put to the back of the mind with a 'crossing the bridge when I get there' (CpI5) attitude, although this procrastination seems unlikely 
to reduce cognitive demand in the long run. The instructors prioritise the need for adaptation primarily on safety, then on educational and logistical demands, in varying order. CpI1explained the interaction of these factors when adapting a session:

I think it's nice for them to feel trusted. It's nice for me to gauge how much [trust] they can have at this early stage. Um, yeah, I guess they were really keen to go in for a second time. It's again a bit of progression... the conditions, they really are quite calm, y'know, not ebbing too much. There was what - four members of centre staff down there; three throw bags.

A desire to remain in control of safety is central to the CpIs' reasoning concerning preaction and in-action decision making. CpI2 commented as follows:

There's a height you could have fallen off; there's more slipperier rock that you could slip on. It was low water levels, which was pretty safe when we were there anyway, but I just think personally, that's something that I would like to have control over rather than open it up to that group.

Furthermore, emotional safety is essential; CpI6 described 'stretching them [the group], but not pushing them too much today 'cause I want them to have fun and not be fearful'. Safety (both physical and emotional) is a priority and at the forefront of CpI's decision making

The CpI demonstrates a desire for cognitive efficiency in in-action decision making by utilising their own experience and community of practice $(\mathrm{CoP})$. CpI3's comments show a pattern matching a naturalistic style of decision making: 'I think it was more from my experience of doing very similar work with similar age groups in similar environments'. As highlighted earlier, the use of heuristics also supports the notion of 'efficient' naturalistic decision making (Klein 2015). 
CpIs evidenced an understanding of their decision making processes in highlighting their metacognition. The level of metacognition, however, or at least their ability to articulate it, varied. CpI5explained, 'I don't think that's describable. I don't think that's... I really don't think that I can say that now'. CpI highly value reflection (possibly due to the centrality of reflection within their organisation pedagogic approach and philosophy). They had either reflected on the session prior to the interview (often using someone from their CoP as a critical friend; Costa and Kallick 1993) - 'we actually chatted about it later, on the way back, and realised that that wasn't really an option' (CpI3) - or were actively reflecting on the session during the interview, likely prompted by the questions. During the interview, CpI1 reflected as follows:

Um, yeah, I guess a little bit of it... it is just a little bit of routine. That's what I pack for on a Monday. Um... And thinking about it, maybe I should think a bit more [about] why I am choosing that activity, 'cause you know our whole week is set out why... y'know, I wouldn't go to rocks... y'know... you think about what you're doing, whereas maybe on a Monday, it is a bit routine.

These unfinished trains of thought may display reflection. CpI1's mid-reflection, recognising the situation and consequently increasing self-awareness. Reflecting the As organisational culture, cited earlier these CpI may be particularly open or practised in on action reflection. .

The individual characteristics of each instructor, their skills, experiences, values, (ontology, epistemology, and personality), also contribute to their thought processes and, therefore, their acceptance of and desire to be adaptable. Their epistemology underpins CpI's professional practice (supported by Collins, et al 2014; Sinfield et al 2019; Taylor and Garrat 2010). There are several shared themes across the CpI's 
working philosophies. Firstly, the desire to do a good job, 'What do we do in that half an hour to get the best value for the young people?' (CpI4). Secondly, a valuing of progression, 'It means we can build up to bigger things, so they're more likely to push themselves' (CpI6) Thirdly, trust 'Building that rapport and trust is really important, so they feel safe, and so they can enjoy it' (CpI6), and finally valuing a challenge, by choice; 'The rest stayed climbing to continue to push themselves a bit more' (CpI3). The continuity amongst CpI's values and epistemologies suggests that they may have been developed through training, professional or personal experiences and that they are a characteristic of adaptive expertise in these outdoor instructors that may not be limited to just the rather than solely ExI.

\section{Results: Part 2b}

\section{More Experienced instructors}

Results comprise 164 codified units leading to 27 low-order themes, nine midorder themes, and three high-order themes, with the single overarching theme of situational awareness. These are illustrated in the thematic table and map (Table 7 and Figure 2, respectively).

Insert Table 7 close to this point Insert Figure 2 close to this point

\section{Discussion}

Comprehension of situational demands generated by the environment, individual student needs, and session objectives are an overarching theme pervading the practice of all ExI in this study. However, safety considerations are imbedded as part of the whole instructional process rather than a discrete aspect.

ExI create a straw man plan that provides a functional framework enabling initial activity by accommodating session aims, anticipated conditions, knowledge of 
students' needs and wants, and putting in place logistics but that can be fundamentally adapted once the reality of conditions and clients in those conditions had been observed and experienced. The extent and detail of the straw man plans vary depending upon the instructor's knowledge of the students, with unknown students a more flexible and adaptable plan is constructed. ExI1 explained: 'I ran it thinking they might know a bit more, but in fact they didn't, so it wasn't ideal to be on the steeper stuff to start with, but it was fine; I managed.' ExI1 involves known students in the construction and adaptation of a plan prior to an activity: 'basically, we had had quite an email conversation. We had also had a bit of a real conversation on a recent intermediate course too.'

The initial activity, thus, allows the quality of information gathered to be verified and critical environmental factors to be identified and accommodated. Subsequently, the straw man plan is reconstructed to reflect the reality of situational demands in context the straw man plan is designed to be de-constructed and then reconstructed.

'I had a plan in my mind of what I wanted to cover. I didn't have a plan necessarily in the timing of each bit. And I knew I had to give myself some time to set up some things that I'm not quite so familiar with. So, in terms of the structure of the day, with Claire, we probably ironed out the actual sequence of events in the staff meeting. But as you see, these all changed.' (ExI3

A sophisticated dendritic decision making process overlays, challenges, and develops the straw man plan in context. This conceptual process seems consistent with Hatano and Inagaki (1984/1986), who stated that a central feature of adaptive expertise is consensus on the notion that adaptive expertise emanates from a well-developed 
conceptual understanding and associated knowledge structures that are contextually sensitive and malleable.

Critical decisions points (nodes) identified in the planning process are integrated into practical tasks through episodes of questioning during the session. ExI's interpretation of responses and experience of instructing and leading the activity in a range of conditions and venues inform the approach, selected from a range of options in the following sub-session. ExI2 stated, 'there are places where it is much easier to do certain moves and places where it is much harder to do certain moves'. ExI2 indicated the need to create and maintain an appropriate learning environment that is safe, effective, and congruent with their teaching philosophy.

ExI amalgamates four factors in a complex matrix to fully comprehend the demands of a situation in context and directly inform their actions in the short, mid, and longer terms. First, there are the individual's motivational factors with the needs of the other individuals within the group. The second factor is maintaining an appropriate 'span of control' to manage the practicalities of individualised and differentiated teaching, create and optimise learning opportunities, and attend to the short, mid, and long term developmental needs of each individual. Third, the instructor's epistemology and personal views on the nature of adventure inform how content is prioritised, sequenced, framed, and presented. ExI 5 described the following: 'I suppose I've been more environment-driven rather than motor skills, sort of technique-driven.' The fourth factor is having an acute situational awareness of the critical risk factors to balance risks against the beneficial learning that might come from exposure to such factors in a 'riskbenefit' analysis. If needed, ExI act swiftly to maintain an appropriate balance and reduce the risk to an acceptable level. 


\section{General Discussion}

In comparing these two groups there are critical areas of overlap and implications for the education of outdoor instructors.

\section{Planning}

Both groups of instructors described making plans before engaging in activities, with ExI creating a straw man plan in anticipation of re-planning and structuring the session, and $\mathrm{CpI}$ constructing fixed plans. $\mathrm{CpI}$ displayed a more significant emotional investment in their plan, making adjustments to delivery style rather than the plan itself. As CpI4 explained, 'engagement with the belaying was maybe not consistent enough for it to be safe for a prolonged period, even with the bell ringing, and so it ended up being a switch to instructor-led belaying'. The current practices on many instructor education programmes of creating rigid lesson plans rather than preparing adaptable plans appears to encourage an inappropriate approach. A similar message may actually come from the structure of instructor education programmes, namely that they are heavily structured with a high curriculum content that illustrates a teaching and learning approach that is in direct contrast to the reality of the $\mathrm{CpI}$ and ExI practices. Planning for adaptability and demonstrating flexibility in training and education programmes would appear to be an important starting point.

$\mathrm{CpI}$ reduce their cognitive demands by planning out the unknowns which, in-turn, reduces adaptability. In contrast, the ExI can recognise and efficiently manage these 'unknowns' - reflecting a high level of situational awareness. The necessity in instructor training would be to generate a level of awareness that includes a comprehension of the factors that create the situation as well as a 
capacity to predict how that situation will change both as the environment and students develop. Inherent in this position would be the need to manage and be capable of managing the high cognitive loads associated with coaching practice in this context. This could logically enable learning opportunities are recognised and capitalised as they arise or are predicted.

In both groups, adaptations are made to create the best learning opportunities for the group though the focus varies. $\mathrm{CpI}$ explicitly prioritise safety above learning through an explicit process of risk mitigation, while ExI manage safety less explicitly and appear reliant on a nuanced comprehension of situational demands that facilitate a risk versus benefit decision based on a comprehension of the benefit of a proposed course of action. Clearly a comprehension of the potential benefit of a course of action lies at the heart of this decision and may dictate a shift from risk assessment to risk and benefit comprehension. This represents a move beyond the situational awareness cited above and reflects a comprehension and prediction of the situational demands. The different professional contexts in which CpI and ExI work may also affect their adaptations. Reflecting their status, ExI work in a context that appears to have fewer logistical constraints, where the aims are predominantly learner-driven and their qualification confers greater trust in their judgements and decisions.

Conversely, CpI work within tighter logistical and institutional constraints with aims derived from extrinsic demands (e.g. the organisation) (Sinfield et al. 2019). It is difficult to know if the instructor's levels of adaptability affects the context in which they work or if the differences in these contexts reflect the instructor's flexibility and adaptability. We suggest that it is likely a combination of these, with both experience and the working context limiting CpI's level of 
adaptability. Despite these differences, the similarities suggest that both groups of instructors are capable of being adaptive and, possibly, given a more flexible working environment, $\mathrm{CpI}$ would prove to be as adaptable as ExI. It does remain a challenge in instructor education and development, however, given the requirement for security. In particular, the associated focus of training on technical safety skill rather than the development of decision making skills that facilitate more flexible use of less resource for instance, that would be based on a refined situational awareness.

\section{Situational awareness}

As mentioned above, ExI can comprehend the significance of thesituational demands, filtering salient information based on a nuanced situational assessment (perception, comprehension, projection) (Endsley 1997) faster than the $\mathrm{CpI}$. Indeed, the $\mathrm{CpI}$ do not filter information; consequently, they take longer to appraise the situation which, in turn, is cognitively demanding or over loading. Solutions to novel or complex problems are, therefore, slower than in the case of ExI. CpI6 commented, 'with the nature of the route, it's quite difficult to pursue many other options'. Suggesting the range of opportunities provided are not full recognised or appreciated. A way to develop the learning required to refine the situational awareness may be to critically reflect in relation to the situation, its comprehension and evolution.

\section{Reflection}

While both groups of instructors provided evidence that they are reflective practitioners, their styles of reflection differ. CpI predominantly use 'on-action' 
reflection (Schon 1983), whereas ExI generally deploy 'in-action' or 'on-action, incontext' (Collins and Collins 2014). The ExI have more 'space' for in-action reflection, managing the variables and vagaries of their working environment to make use of opportunistic chances to consider or to actively create situations in the session that allow reflection. By contrast, the CpI's 'on-action' reflections (Schon 1983) place any explicit learning of decision post action and thus is not actionable. We surmise that this may be a consequence of managing a more substantial amount of information in action because of the emotional challenges associated with deviation from the plan. The instructor may be obliged to adhere to their plan despite recognising the need to change but not feel able to, a cognitive dissonance. In-action reflection would add to this load for $\mathrm{CpI}$ and is, therefore, not considered a priority. This preference for on-action reflection can be ascribed to the reflective culture engendered within instructor education, a focus on on-action reflection of the effectiveness of the fixed lesson plans mentioned earlier creating shackles that inhibit the adaptability and flexibility required by the situation.

\section{Metacognition}

Metacognition allows for a deep self-awareness - key for instructors to balance situational demands with their ability when making decisions. ExI hold personal philosophies which allow them to be highly metacognitively active and, utilising the high levels of situational awareness without creating a significant cognitive load. Similarly, CpI understand how their philosophies and values impact their decision making, highlighting their metacognitive ability. Their ability to articulate the meta process may not yet match this. CpI5 described this 
mismatch: 'You do something, and I can't always maybe articulate why I have chosen that, but I know the factors and it's led me to that'. The instructor's experience supports the metacognition, their adaptability while also demonstrating a need for greater comprehension of the relationship between those factors.

Despite the diversity of experience and qualifications, both groups demonstrated sophisticated epistemologies and evinced that they are metacognitive active. Given the nature of the adventurous activity and the hyperdynamic environment, reflection and metacognition are learnt early, ideally through a combination of personal activity ( a necessity for instructors), via their community of practice, and formal or informal education programmes. If this is the case, do we need to develop these skills explicitly?

\section{Limitations and further research}

Accepting the limitations cited earlier, the small sample sizes in this study allowed for an in-depth analysis. We propose that further research be done to explore the developmental journey of CpI. It is important to note further limitations in the design that we are unable to address. As this was a pre-post, single intervention, we acknowledge the placebo effect which this may have had. However, it is worth highlighting the status of ongoing professional development with this group of professionals, which would suggest that they are sufficiently critical consumers to make this less likely to be the sole explanation for the effects observed.

\section{Conclusion}

The results reveal both $\mathrm{CpI}$ and ExI to be adaptive to different degrees. However, there were differences between $\mathrm{CpI}$ and ExI in their employment of planning, reflection, metacognition, and situational awareness that influence their 
levels of adaptability. For ExI, the effort required in paying attention to the situation allows more in-action reflection and faster access to, and selection of, relevant options. The ExI demonstrate higher adaptive capacity than CpI, who, whilst operating as adaptive experts, are less adaptive than the ExI. This may be because they fit within rigid organisational structures. These structures may be generated by the instructor themselves and possibly the organisations that employed them. The epistemologies of both groups showed levels of sophistication that underpin their practice. We suggest emanating from the need to be practitioners of adventure sports before training as an instructor at any level. Having drawn attention to the differences in adaptive capacity between the groups we suggest adaptive expertise is a pragmatic description that better suits the nature of expertise in both these groups of instructors. Logically, the approaches used when training and developing these instructors should reflect the need for pedagogic agility.

\section{References}

Abraham, A., and D. Collins. 2011. "Effective Skill Development: How Should Athletes' Skills Be Developed?" In Performance Psychology: A Practitioner's

Guide, edited by D. Collins, A. Button, and H. Richards, 207-229. Oxford: Elsevier. https://doi.org/10.1016/B978-0-443-06734-1.00015-8.

Alexander, P. A., D. L. Schallert, and V. C. Hare. 1991. "Coming to Terms: How Researchers in Learning and Literacy Talk About Knowledge." Review of Educational Research 61 (3): 315-343.

https://doi.org/10.3102/00346543061003315.

Allworth, E., and B. Hesketh. 1999. "Construct-Oriented Biodata: Capturing Changerelated and Contextually Relevant Future Performance." International Journal of 
Selection and Assessment 7 (2): 97-111. https://doi.org/10.1111/1468-2389.00110.

Barnett, S. M., and B. Koslowski. 2002. "Adaptive Expertise: Effects of Type of Experience and the Level of Theoretical Understanding It Generates." Thinking \& Reasoning 8 (4): 237-267. https://doi.org/10.1080/13546780244000088.

Bell, B. S., and S. W. J. Kozlowski. 2008. "Active Learning: Effects of Core Training Design Elements on Self-Regulatory Processes, Learning, and Adaptability." Journal of Applied Psychology 93 (2): 296-316. https://doi.org/10.1037/00219010.93.2.296.

Bell, E., G. Horton, G. Blashki, and B. M. Seidel. 2012. "Climate Change: Could It Help Develop 'Adaptive Expertise'?" Advances in Health Sciences Education 17 (2): 211-224. https://doi.org/10.1007/s10459-010-9245-4.

Bransford, J., S. Derry, D. Berliner, K. Hammerness, and K. L. Beckett. 2005. "Theories of Learning and Their Roles in Teaching." In Preparing Teachers for a Changing World: What Teachers Should Learn and Be Able to Do, edited by L. Darling-Hammond and J. Bransford, 40-87. San Fransisco: Jossey-Bass.

Braun, V., and V. Clarke. 2006. "Using Thematic Analysis in Psychology." Qualitative Research in Psychology 3 (2): 77-101. http://dx.doi.org/10.1191/1478088706qp063oa.

Carbonell, K. B., K. D. Könings, M. Segers, and J. J. G. van Merriënboer. 2016. "Measuring Adaptive Expertise: Development and Validation of an Instrument." European Journal of Work and Organizational Psychology 25 (2): 167-180. https://doi.org/10.1080/1359432X.2015.1036858.

Chi, M. T. H. 2011. "Theoretical Perspectives, Methodological Approaches, and Trends in the Study of Expertise." In Expertise in Mathematics Instruction: An International Perspective. https://doi.org/10.1007/978-1-4419-7707-6_2. 
Christian, E., M. Berry, and P. Kearney. 2017. "The Identity, Epistemology and Developmental Experiences of High-Level Adventure Sports Coaches." Journal of Adventure Education and Outdoor Learning 17 (4): 353-366. https://doi.org/10.1080/14729679.2017.1341326.

Collins, L., H. Carson, and D. Collins. 2016. "Metacognition and Professional Judgment and Decision Making in Coaching: Importance, Application and Evaluation." International Sport Coaching Journal 3 (3): 355-361. https://doi.org/10.1123/iscj.2016-0037.

Collins, L., and D. Collins. 2012. "Conceptualizing the Adventure-Sports Coach." Journal of Adventure Education \& Outdoor Learning 12 (1): 81-93. https://doi.org/10.1080/14729679.2011.611283.

Collins, L., and D. Collins. 2013. "Decision Making and Risk Management in Adventure Sports Coaching." Quest 65 (1), 72-82. https://doi.org/10.1080/00336297.2012.727373.

Collins, L., and D. Collins. 2015a. "Integration of Professional Judgement and Decision making in High-Level Adventure Sports Coaching Practice." Journal of Sports Sciences 33 (6): 622-633. https://doi.org/10.1080/02640414.2014.953980.

Collins, L., and D. Collins. 2015b. "Professional Judgement and Decision making in Adventure Sports Coaching: The Role of Interaction." Journal of Sports Science ePub (October), 1-12. https://doi.org/10.1080/02640414.2015.1105379.

Collins, L., and D. Collins. 2016a. "Professional Judgement and Decision making in the Planning Process of High-Level Adventure Sports Coaching Practice." Journal of Adventure Education and Outdoor Learning 16 (3): 256-268. https://doi.org/10.1080/02640414.2015.1105379.

Collins, L., and D. Collins. 2016b. "The Foci of In-Action Professional Judgement and 
Decision making in High-Level Adventure Sports Coaching Practice." Journal of Adventure Education and Outdoor Learning 17(2), 122-132.

https://doi.org/10.1080/14729679.2016.1227717.

Collins, L., Collins, D., and D. Grecic. 2014. "The Epistemological Chain in HighLevel Adventure Sports Coaches." Journal of Adventure Education and Outdoor Learning 15 (3): 224-238. https://doi.org/10.1080/14729679.2014.950592.

Collins, D. J., L. Collins, and T. Willmott. 2016. "Over Egging the Pudding? Comments on Ojala and Thorpe." International Sport Coaching Journal 3 (1), 90-93.

Collins, L., S. Simon, and H. Carson. 2018. "Para-adventure: A Hyper-Dynamic Problem for the Inclusive Coach." Sport in Society 22 (7), 1165-1182. https://doi.org/10.1080/17430437.2018.1504776.

Costa, L., and B. Kallick. 1993. "Through the Lens of a Critical Friend." Education Leadership. EBSCO Publishing.

Crawford, V. M., M. Schlager, Y. Toyama, M. Riel, and P. Vahey. 2005.

"Characterizing Adaptive Expertise in Science Teaching Introduction and Overview." In American Educational Research Association Annual Conference. Montreal, Canada.

Endsley, M. 1997. "The Role of Situation Awareness in Naturalistic Decision Making." In Naturalistic Decision Making, edited by C. Zsambok and G. Klein, 2969-2283. New Jersey: Lawrence Erlbaum \& Associates.

Feltovich, P. J., M. J. Prietula, and K. A. Ericsson. 2012. "Studies of Expertise from Psychological Perspectives." The Cambridge Handbook of Expertise and Expert Performance, 41-68. https://doi.org/10.1017/cbo9780511816796.004.

Gentner, D., S. Brem, R. W. Ferguson, A. B. Markman, B. B. Levidow, P. Wolff, and K. D. Forbus. 1997. "Analogical Reasoning and Conceptual Change: A Case Study 
of Johannes Kepler." Journal of the Learning Sciences 6 (1): 3-40.

https://doi.org/10.1207/s15327809j1s0601_2.

Gulick, L., and L. Urwick, eds. 1937. Papers on the Sciene of Administration. Papers on the Science of Administration. New York: Institute of Public Administration.

Hatano, G., and K. Inagaki. 1986. "Two Courses of Expertise." In Child Development and Education in Japan, edited by H. Stevenson, H. Azuma, and K. Hakuta, 262272. New York: Freeman. https://doi.org/10.1002/ccd.10470.

Hatano, G., and Y. Oura. 2003. "Commentary: Reconceptualizing School Learning." Educational Researcher 32 (8): 26-29. https://doi.org/10.3102/0013189X032008026.

Hutton, R., P. Ward, J. Gore, P. Turner, R. Hoffman, A. Leggatt, and G. Conway. 2017. "Developing Adaptive Expertise: A Synthesis of Literature and Implications for Training." In 13th International Conference on Naturalistic Decision Making, 8186. Bath, UK.

Kahneman, D., and A. Tversky. 1974. "Judgment Under Uncertainty: Heuristics and Biases." Science 185 (4157): 1124-1131.

Klein, G. 2015. "A Naturalistic Decision Making Perspective on Studying Intuitive Decision Making." Journal of Applied Research in Memory and Cognition 4 (3): 164-168. https://doi.org/10.1016/j.jarmac.2015.07.001.

Levitt, H. M., S. L. Motulsky, F. J. Wertz, S. L. Morrow, and J. G. Ponterotto. 2017. "Recommendations for Designing and Reviewing Qualitative Research in Psychology: Promoting Methodological Integrity." Qualitative Psychology 4 (1): 2-22. https://doi.org/10.1037/qup0000082.

Lin, X., D. L. Schwartz, and G. Hatano. 2005. "Toward Teachers' Adaptive Metacognition." Educational Psychologist 40 (4): 245-255. 
https://doi.org/10.1207/s15326985ep4004_6.

McCammon, I. 2001. "Decision Making for Wilderness Leaders: Strategies, Traps and Teaching Methods." National Outdoor Leadership School, 16-29.

Morrow, S. L. 2005. "Quality and Trustworthiness in Qualitative Research in Counseling Psychology." Journal of Counseling Psychology 52 (2): 250-260. https://doi.org/10.1037/0022-0167.52.2.250.

Nash, C., R. Martindale, D. Collins, and A. Martindale. 2012. "Parameterising Expertise in Coaching: Past, Present and Future." Journal of Sports Sciences 30 (10): 985994. https://doi.org/10.1080/02640414.2012.682079.

Ojala, A.-L., and H. Thorpe. 2015. "The Role of the Coach in Action Sports: Using a Problem-Based Learning Approach." International Sport Coaching Journal 2 (1): 64-71. https://doi.org/10.1123/iscj.2014-0096.

Olsen, S., and J. Rasmussen. 1989. "The Reflective Expert and the Pre novice: Notes on Skill-, Rule-, and Knowledge-Based Performance in the Setting of Instruction and Training." In Developing Skills with Information Technology, edited by L. Bainbridge and S. Ruiz-Quintanilla, 9-33. Chichester: Wiley.

Pierce, W. 1991. Span of Control and the Operational Commander: Is It More Than Just a Number? (Monograph). Kansas.

Pulakos, E., S. Arad, M. Donovan, and K. Plamondon. 2000. "Adaptability in the Workplace: Development of a Taxonomy of Adaptive Performance." Journal of Applied Psychology 85 (4): 612-624. https://doi.org/10.1037/0021-9010.85.4.612.

Pulakos, E., N. Schmitt, D. Dorsey, S. Arad, W. Borman, and J. Hedge. 2009. "Predicting Adaptive Performance: Further Tests." Human Performance 15 (4): 339-366. https://doi.org/10.1207/S15327043HUP1504.

Reder, L. M., and C. D. Schunn. 1993. "Bringing Together the Psychometric and 
Strategy Worlds: Predicting Adaptivity in a Dynamic Task." In Attention and Performance XVII: Cognitive Regulation of Performance: Interaction of Theory and Application, edited by D. Gopher and A. Koriat, 315-342. Cambridge: MIT Press.

Robson, C., and K. McCartan. 2016. Real-World Research: A Resource for Users of Social Research Methods in Applied Settings. 4th ed. Chichester: Wiley.

Sandelowski, M. 1995. "Focus on Qualitative Methods Qualitative Analysis: What It Is and How to Begin." Research in Nursing \& Health 18 (4): 371-375. https://doi.org/10.1002/nur.4770180411.

Schon, D. 1983. The Reflective Practitioner: How Professionals Think in Action. New York: Basic Books.

Schwartz, D. L., J. D. Bransford, and D. Sears. 2005. "Efficiency and Innovation in Transfer." In Transfer of Learning from a Modern Multidisciplinary Perspective. Simon, S., L. Collins, and D. Collins, 2017. "Observational Heuristics in a Group of High-Level Paddle Sports Coaches." International Sport Coaching Journal 4 (2): 235-245. https://doi.org/10.1123/iscj.2017-0012.

Sinfield, D., J. Allen, and L. Collins. 2019. "A Comparative Analysis of the Coaching Skills Required by Coaches Operating in Different Non-competitive Paddlesport Settings." Journal of Adventure Education and Outdoor Learning, https://doi.org/10.1080/14729679.2019.1609998.

Sonnentag, S., C. Niessen, and J. Volmer. 2012. "Expertise in Software Design." In The Cambridge Handbook of Expertise and Expert Performance. https://doi.org/10.1017/cbo9780511816796.021.

Stokes, C. K., T. R. Schneider, and J. B. Lyons. 2010. "Adaptive Performance: A Criterion Problem." Team Performance Management 16 (3/4): 212-230. 
https://doi.org/10.1108/13527591011053278.

Taylor, B., and D. Garrat. 2010. "The Professionalization of Sports Coaching: Definitions, Challenges and Critique." In Sports Coaching: Professionalisation and Practice, edited by J. Lyle and C. Cushion. Edinburgh: Churchill Livingstone Elsevier.

Tozer, M., I Fazey, and J. Fazey. 2007. "Recognizing and Developing Adaptive Expertise within Outdoor and Expedition Leaders." Journal of Adventure Education and Outdoor Learning 7 (1): 55-75. https://doi.org/10.1080/14729670701349780.

Trotter, M. J., P. M. Salmon, N. Goode, and M. G. Lenné. 2017. "Distributed Improvisation: A Systems Perspective of Improvisation 'Epics' by Led Outdoor Activity Leaders." Ergonomics 61 (2): 295-312. https://doi.org/10.1080/00140139.2017.1355071.

Willis, G., T. DeMatio, and B. Harris-Kojetin. 1999. "Is the Bandwagon Headed to the Methodological Promised Land? Evaluating the Validity of Cognitive Interviews." In Cognition and Research, edited by M. G. Sirken, D. J. Hermann, S. Schechter, N. Schwarz, J. M. Tanur, and R. Tourangeau, 133-153. New York: Wiley.

Wineburg, S. 1998. "Reading Abraham Lincoln: An Expert/Expert Study in the Interpretation of Historical Texts." Cognitive Science 22 (3): 319-346. https://doi.org/10.1207/s15516709cog2203_3. 


\begin{tabular}{|c|c|}
\hline Dimension & $\begin{array}{l}\text { Experience example and } \\
\text { research support }\end{array}$ \\
\hline Solving problems creatively & $\begin{array}{l}\text { Having to solve problems for } \\
\text { which there are no easy or } \\
\text { straightforward solutions, } \\
\text { wicked or messy problems } \\
\text { (Simon et al. 2017) }\end{array}$ \\
\hline $\begin{array}{l}\text { Dealing with uncertainty or } \\
\text { unpredictable work situations }\end{array}$ & $\begin{array}{l}\text { Operating with incomplete and } \\
\text { complex information regarding } \\
\text { a situation (Collins and Collins } \\
\text { 2015a, 2015b, 2016a) }\end{array}$ \\
\hline $\begin{array}{l}\text { Learning new tasks, technologies, } \\
\text { and procedures }\end{array}$ & $\begin{array}{l}\text { The synergy and dynamic } \\
\text { nature of task, environment, } \\
\text { and the individual generate } \\
\text { unique challenges that require } \\
\text { the development of novel } \\
\text { solutions (Collins and Collins } \\
\text { 2016a, 2016b) }\end{array}$ \\
\hline $\begin{array}{l}\text { Demonstrating interpersonal } \\
\text { adaptability }\end{array}$ & $\begin{array}{l}\text { Contending with the 'needs } \\
\text { versus wants' balance with } \\
\text { clients (Simon et al. 2017) }\end{array}$ \\
\hline $\begin{array}{l}\text { Demonstrating cultural } \\
\text { adaptability }\end{array}$ & $\begin{array}{l}\text { Learning the rules for } \\
\text { appropriate interaction given } \\
\text { the apparent counter culture, } \\
\text { though this may not be as } \\
\text { suggested (see Collins, Collins, } \\
\text { and Willmott 2016; Ojala and } \\
\text { Thorpe 2015) }\end{array}$ \\
\hline $\begin{array}{l}\text { Demonstrating physically } \\
\text { orientated adaptability }\end{array}$ & $\begin{array}{l}\text { Outdoor instructors are required } \\
\text { to participate in sport alongside } \\
\text { their students as part of the } \\
\text { coaching process (Collins and } \\
\text { Collins 2012, 2016b) }\end{array}$ \\
\hline Handling work stress & $\begin{array}{l}\text { Roles of the adventure sports } \\
\text { coach and leader are multi- } \\
\text { functional (Collins and Collins } \\
\text { 2012) }\end{array}$ \\
\hline $\begin{array}{l}\text { Handling emergencies or crisis } \\
\text { situations }\end{array}$ & $\begin{array}{l}\text { Making quick decisions under } \\
\text { life threatening conditions } \\
\text { (Collins and Collins 2013) }\end{array}$ \\
\hline
\end{tabular}

Table 1; Examples from research highlighting adaptive expertise in the outdoor instructor context (Adapted from Pulakos et al. 2000, 2009) 
Question 1: During past projects, I was able to develop and integrate new knowledge with what I had learned in the past.

Question 2: During past projects, I concerned myself with the latest development in the domain of my discipline.

Question 3: During past projects, I gained a better understanding of concepts in my discipline.

Question 4: During past projects, I realised that the knowledge in my discipline keeps on developing.

Question 5: During past projects, I realised that I need to learn continuously to become and stay an expert in my field.

Question 6: During past projects, I showed that I am willing to keep on learning new aspects related to my discipline.

Question 7: During past projects, I applied my knowledge in new and unfamiliar situations in areas related to my discipline with a degree of success.

Question 8: During past projects, I focused on new challenges.

Question 9: During past projects, I approached it like other projects I had worked on in the past.

Question 10: During past projects, I was able to continue performing at a high level when confronted with unfamiliar situations or tasks.

Question 11: During past projects, I was able to apply my knowledge flexibly to the different tasks within the project.

Table 2, Adaptive expertise inventory (Carbonell et al. 2016)

\begin{tabular}{|c|c|c|c|c|}
\hline Status & $\mathrm{N}$ & Mean & Std. Deviation & $\begin{array}{l}\text { Std. Error } \\
\text { Mean }\end{array}$ \\
\hline More experienced & 29 & 50.3448 & 3.22131 & .59818 \\
\hline Less experienced & 26 & 45.5385 & 4.17833 & .81944 \\
\hline
\end{tabular}

Table 3; Descriptive analysis results of Adaptive Expertise Inventory 
Levene's Test for Equality

of Variances t-test for Equality of Means

\begin{tabular}{|c|c|c|c|c|c|c|c|}
\hline $\mathrm{F}$ & Sig. & $t$ & Df & Sig. (2-tailed) & Mean Difference & $\begin{array}{l}\text { Std. Error } \\
\text { Difference }\end{array}$ & $\begin{array}{l}95 \% \text { Confidenc } \\
\text { of the Differenı } \\
\text { Lower }\end{array}$ \\
\hline \multirow[t]{2}{*}{2.435} & .125 & 4.8 & & $>.001$ & 4.80637 & 1.00030 & 2.80002 \\
\hline & & 5 & & & & & \\
\hline
\end{tabular}

Table 4; Significance of results 


\begin{tabular}{|c|c|c|}
\hline Question & Prompts & Notes \\
\hline $\begin{array}{l}\text { Can you describe that } \\
\text { aspect of your session? }\end{array}$ & $\begin{array}{l}\text { How did you do that? } \\
\text { Why did you do that? }\end{array}$ & $\begin{array}{l}\text { Detailed description or } \\
\text { broad? } \\
\text { Linear or nuanced? }\end{array}$ \\
\hline $\begin{array}{l}\text { What other options were } \\
\text { available to you }\end{array}$ & $\begin{array}{l}\text { What options did you } \\
\text { consider? } \\
\text { Were there any options you } \\
\text { did not consider? } \\
\text { Did you rule anything out } \\
\text { initially? } \\
\text { How? } \\
\text { Why? }\end{array}$ & $\begin{array}{l}\text { Range and scope of } \\
\text { options } \\
\text { Motivations } \\
\text { Ease of recall } \\
\text { Detailed description } \\
\text { Number of options }\end{array}$ \\
\hline $\begin{array}{l}\text { What factors influenced } \\
\text { your choice of options? }\end{array}$ & $\begin{array}{l}\text { What led you to choose that } \\
\text { option? } \\
\text { What deterred you from } \\
\text { other options? } \\
\text { How did you choose? } \\
\text { Why? }\end{array}$ & $\begin{array}{l}\text { Time } \\
\text { Observation } \\
\text { Conditions } \\
\text { Motivation } \\
\text { Individualised or group } \\
\text { focused? } \\
\text { Profile building } \\
\text { Success/failure }\end{array}$ \\
\hline $\begin{array}{l}\text { What if...? } \\
\text { (Creativity question) }\end{array}$ & $\begin{array}{l}\text { How might you adapt to } \\
\text { different } \\
\text { weather/group/purpose? } \\
\text { What might you do in a } \\
\text { crisis situation? }\end{array}$ & $\begin{array}{l}\text { Higher water levels } \\
\text { Older/younger group } \\
\text { Challenging behaviour } \\
\text { Different session aim } \\
\text { Injury } \\
\text { Danger }\end{array}$ \\
\hline
\end{tabular}

Table 5; Interview questions, prompts, and notes 


\section{Low-Order Themes}

Profiling and managing group needs

Preoccupation with safety

Working in dynamic environmental conditions

Working in time pressured situations

Accommodating organisational constraints

Working to externally specified aims

Community of practice (working with another instructor)

Efficient decision-making

Beginning with a detailed plan

Personal philosophies and values influencing DM

Metacognition/Understanding of one's own

decision-making

Using past experience to inform Decision Making

Reflection on action predominantly

\section{Mid-Order Themes}

Comprehension of the situational awareness and demands
Nested decision-making process

Metacognition

Table 6 Thematic analysis of less experienced instructors 
Participant set objectives for the session or sessions

Coach set objectives for the session or sessions

Syllabus driven objectives for the session or sessions

Weather past and present that will be impacting the session

Forecast weather and any changes that will be impacting the session

Surface conditions that currently exist and how they might change during the session

Known information about each individual within the session

Missing information about each individual within the session

Quality and reliability of information about each individual within the sessions

Observation of behaviour of each individual to task set

Answer to questioning by each individual to questions posed

A general engagement with the coaching process

Experience of activity in a broad range of conditions

Experience of venues in a broad range of conditions

Experience of coaching and leading in the current context

Ownership of learning

Managing both group and individual needs

Context of the learning within the leaners progression and the sessions location within the coaching episode

Span of control in context of session

Opportunistic coaching opportunities

How the learning is framed and presented

Prioritising of content and order of addressing material

Personal Ontology of the coach

Personal epistemology of the coach

Identification of risk factors

Balancing the risk against potential learning - Risk benefit analysis

Safety Overview and management
Aims and Objectives for the session or sessions

Key environmental factors affecting the session

Known or Unknown participants

Behavioural clues given by those being coached

Coaches Experienced Informed knowledge

Motivational considerations including autonomy

Coaching process manipulation by coach to facilitate effec session delivery

Considered and explicit Personal Philosophy

Situational Awareness and Demands

Table 7; Themetaic analysis of more experienced Instructors 